\title{
Reactivity of Phenol Allylation Using Phase-Transfer Catalysis in Ion-Exchange Membrane Reactor
}

\author{
Ho Shing Wu and Yeng Shing Fu \\ Department of Chemical Engineering and Materials Science, Yuan Ze University, Zhongli, Taiwan \\ Correspondence should be addressed to Ho Shing Wu, cehswu@saturn.yzu.edu.tw \\ Received 16 February 2012; Revised 16 May 2012; Accepted 17 May 2012 \\ Academic Editor: Victor V. Nikonenko
}

Copyright ( $) 2012$ H. S. Wu and Y. S. Fu. This is an open access article distributed under the Creative Commons Attribution License, which permits unrestricted use, distribution, and reproduction in any medium, provided the original work is properly cited.

This study investigates the reactivity of phenol allylation using quaternary ammonium salt as a phase-transfer catalyst in three types of membrane reactors. Optimum reactivity and turnover of phenol allylation were obtained using a respond surface methodology. The contact angle, water content, and degree of crosslinkage were measured to understand the microenvironment in the ion exchange membrane.

\section{Introduction}

Phase-transfer catalytic techniques have been used in manufacturing industry synthesis processes, such as insecticidal and chemical production [1-3]. However, a traditional liquid-liquid phase-transfer catalytic reaction has many disadvantages, because separating the catalyst and purifying the reaction system are difficult. Hence, the liquid-solid-liquid phase-transfer catalyst technique was developed. Although this type of catalyst is easy to use and recover from a solution, the reactant pore diffusion in the catalyst affects the reaction and decreases the reaction rate. A catalyst immobilized in an ion exchange membrane could solve these problems.

When a catalyst is immobilized in an inert membrane pore, the catalytic reactivity and separation functions are engineered in a complex system. The membrane technique offers advantages of (i) separating the catalyst from the reaction solution, (ii) maintaining phase separation to minimize the potential of emulsions forming, and (iii) a high surface area per unit volume of the reactor. Furthermore, Zaspalis et al. [4] reported that a reaction using a membrane catalyst could be 10 times more active than a pellet catalyst reaction. Yadav and Mehta [5] presented a theoretical and experimental analysis of capsule membrane phase-transfer catalysis for the alkaline hydrolysis of benzyl chloride to benzyl alcohol. Okahata and Ariga [6] examined the reaction of sodium azide with benzyl bromide in the presence of a capsule membrane with pendant quaternary ammonium groups and polyethylene glycol groups on the outside. A capsule membrane is unsuited to mass industrial production because of the inconvenience of working with capsules.

Various methods of preparing ion-exchange membranes for different purposes have been proposed and practiced by industry. One of these methods is copolymerizing divinylbenzene and other vinyl monomers (e.g., styrene, chloromethylstyrene, and vinylpyridine) into a membranous copolymer using the paste method and then introducing ion-exchange groups into the copolymer [7-9]. The polymer solution (which contains polymers with ion-exchange groups and other polymers) is then cast on a flat plate to remove the solvent $[10,11]$. Most commercial anionexchange membranes contain benzyl trimethylammonium or $N$-alkyl pyridinium groups as anion-exchange groups and are cross-linked with divinylbenzene. The membrane backbone polymer is hydrophobic because of aromatic or heterocyclic groups and the active ion-exchange group is hydrophilic. A study $[12,13]$ that used commercially and laboratory-produced membranes as phase-transfer catalysts in the allylation of phenol showed that the reactivity of quaternary ammonium catalysts in the ion-exchange membrane was lower than that of general phase-transfer catalysts because the ion-exchange group was hydrophilic. The types 

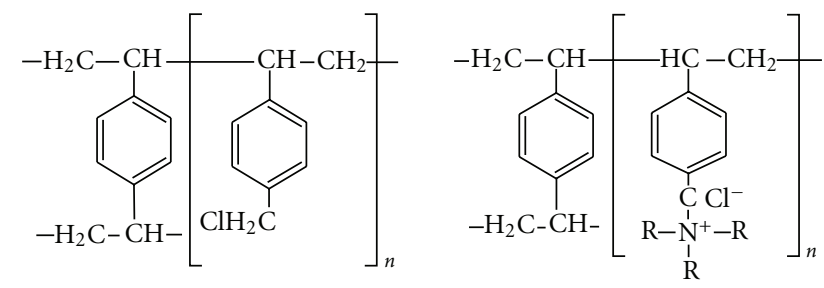

FIgURE 1: The structure of the base membrane and anion exchange membrane.

of ion-exchange groups were hydrophobic and hydrophilic to test the reactivity of phenol allylation. This study presents a discussion on the reactor design problem in a membrane reactor in a two-phase system and examines the relationship between the reactivity of phenol allylation and the membrane reactor. This study also uses membrane properties and the transfer of phenolate ions in the membrane to research the reactivity of quaternary ammonium catalysts in the membrane.

\section{Experimental Section}

2.1. Materials. Allyl bromide (Fluka, 99.5\%), phenol (RDH, 99\%), chloromethylstyrene (Aldrich, 97\%), and allyl phenyl ether (PhOR, Aldrich, 99\%) were provided by the indicated suppliers. Anion-exchange membrane A-172 (a polymer of 1-methyl-4-vinyl-pyridinium crosslinked with 1,4divinylbenzene) was purchased from ASAHI CHEM Ind. Co. Ltd. (Japan). The characteristics of the A-172 membrane were thickness $0.12-0.15 \mathrm{~mm}$; ion-exchange capacity $1.8-1.9 \mathrm{meq} / \mathrm{g}$ of dry membrane; water content $24 \%-25 \%$; electrical resistance $1.7-20 \Omega / \mathrm{cm}^{2}$; character: monoanion permselectivity membrane; reinforcement PP fabric.

\section{Preparation of Anion Exchange Membrane}

The preparation procedure was identical to that described by H. S. Wu and Y. K. Wu (2005) [13]. Four types of anion exchange membranes with different amine functional groups (trimethylamine (TMA), triethylamine (TEA), tri- $n$ propylamine (TPA), and tri- $n$-butylamine (TBA) were prepared by a reaction of a membranous copolymer composed of chloromethylstyrene (CMS type) and divinylbenzene with various tertiary amines (TMA, TEA, TPA, and TBA). Figure 1 shows the structure of the base membrane and anion exchange membrane. H. S. Wu and Y. K. Wu [13] described the synthesis of the base membrane and the process of immobilizing amine in the base membrane.

\section{Water Content in the Membrane}

The membrane was washed with deionized water and then immersed in deionized water for $60 \mathrm{~min}$. This process was completed twice. The wet membrane was weighed after removing its surface moisture. This process was conducted at least three times to obtain accuracy within 5\%. The dry membrane was weighed after drying at $60^{\circ} \mathrm{C}$. Water content was calculated using $W_{C}(\%)=\left(W_{W}-W\right) / W_{W} \times 100$, where $W_{C}, W_{W}$, and $W$ are water content in the membrane, weight of the wet membrane after wiping, and weight of the dry membrane, respectively.

\section{Kinetics of Phenol Allylation in a Membrane Reactor}

Figure 2 shows the experiment apparatus of a membrane reactor. An external circulatory bath was the membrane reactor thermostat to maintain isothermal conditions. An aqueous solution $\left(55 \mathrm{~cm}^{3}\right)$ of sodium hydroxide $(0.00334 \mathrm{~mol})$ and phenol $(0.002 \mathrm{~mol})$ was prepared and introduced into the membrane reactor, which was set at the desired temperature. Quantities of allyl bromide $(0.03 \mathrm{~mol})$, dichloroethane $\left(55 \mathrm{~cm}^{3}\right)$, and diphenyl ether (internal standard) were prepared and set to the desired temperature and then introduced into the reactor. The interfacial area between the two phases was $6.0 \times 10^{-4} \mathrm{~m}^{2}$. The reaction temperature was $45-65^{\circ} \mathrm{C}$. The reaction rate did not decrease below $5 \%$ after repeating four reaction runs.

For a kinetic run, a sample was withdrawn from the reaction solution at selected time intervals. The sample $\left(0.1 \mathrm{~cm}^{3}\right)$ was immediately added to dichloroethane $\left(0.3 \mathrm{~cm}^{3}\right)$ to quench the reaction. The organic phase content was then quantitatively analyzed with a high-performance liquid chromatograph using the internal standard method. The accuracy of these analytical techniques was within $2 \%$ $3 \%$ and the data were correctly reproduced within $5 \%$ of the values reported by this study. Liquid chromatography was conducted with a Shimadzu LC-SPD-10A instrument using a column packed with Phenomenex C12 $(150 \times$ $4.6 \mathrm{~mm}$, SYNERGI $4 \mathrm{u}$ MAX-RP 80A, USA). The eluant was $\mathrm{CH}_{3} \mathrm{OH} / \mathrm{H}_{2} \mathrm{O}=3 / 1$ with a flow rate of $1.0 \mathrm{~cm}^{3} \mathrm{~min}^{-1}$ monitored at $254 \mathrm{~nm}$ (UV detector).

\section{Measurement of Contact Angle}

Numerous types of membranes (the A172 membrane and laboratory-produced membranes) can be used to measure contact angles. A syringe needle was used to draw solvents and then the syringe was squeezed five times until it was clean. Solvents were drawn into the syringe needle without bubbles. Membranes were placed on a table with a flat surface and the syringe needle was placed on the apparatus. One drop was dropped onto the membrane until the shape of the drop did not change. The contact angle was recorded. Measurements were taken three times.

\section{Results and Discussion}

Phase-transfer catalysis is a useful tool in organic synthesis and has many applications in commercial processes. However, it cannot separate a product from its catalyst. Hence, liquid-solid-liquid phase-transfer catalysis was developed to immobilize the quaternary ammonium group onto the resin and membrane [12-15]. Wu and Wang [14] proposed two 


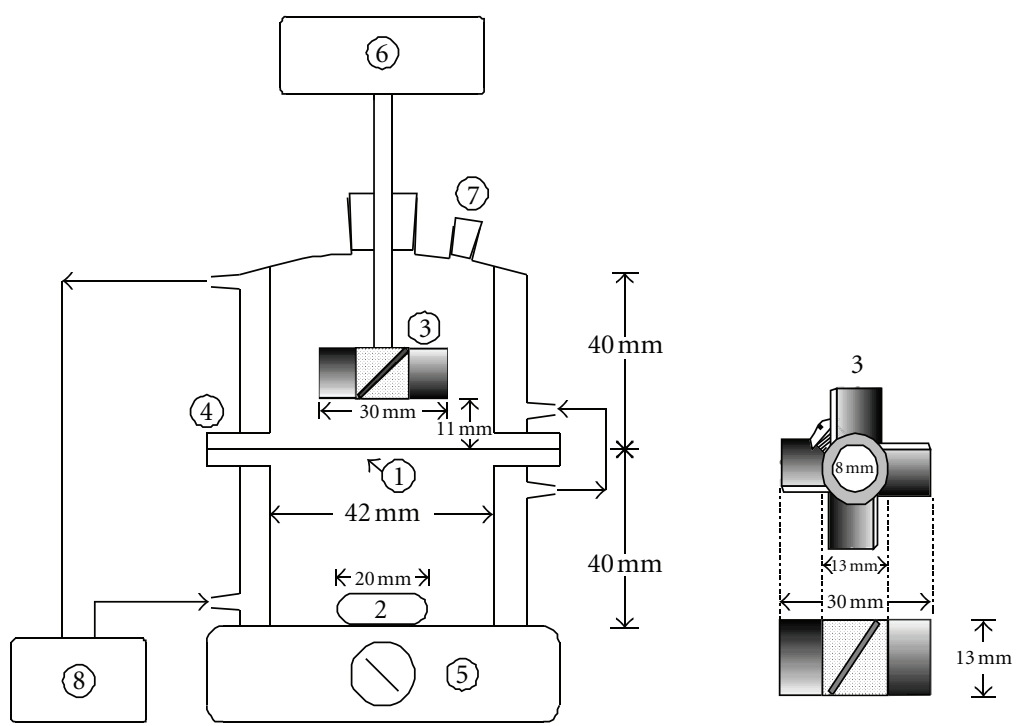

(a)

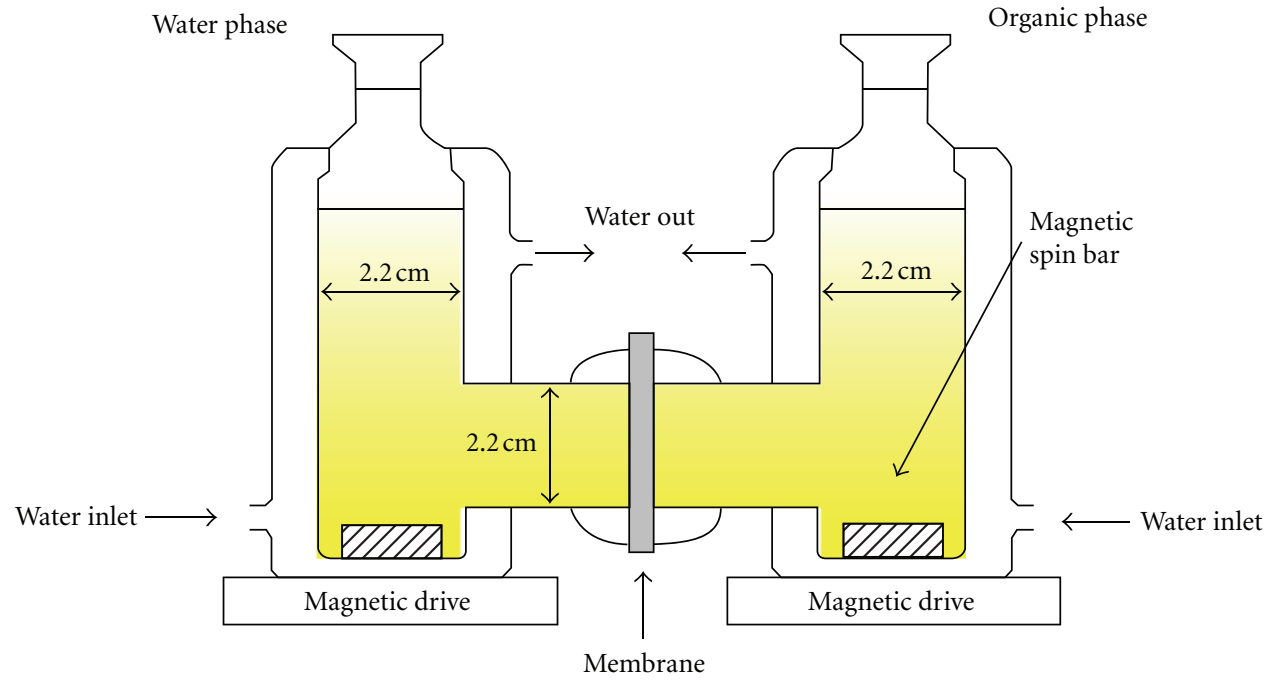

(b)

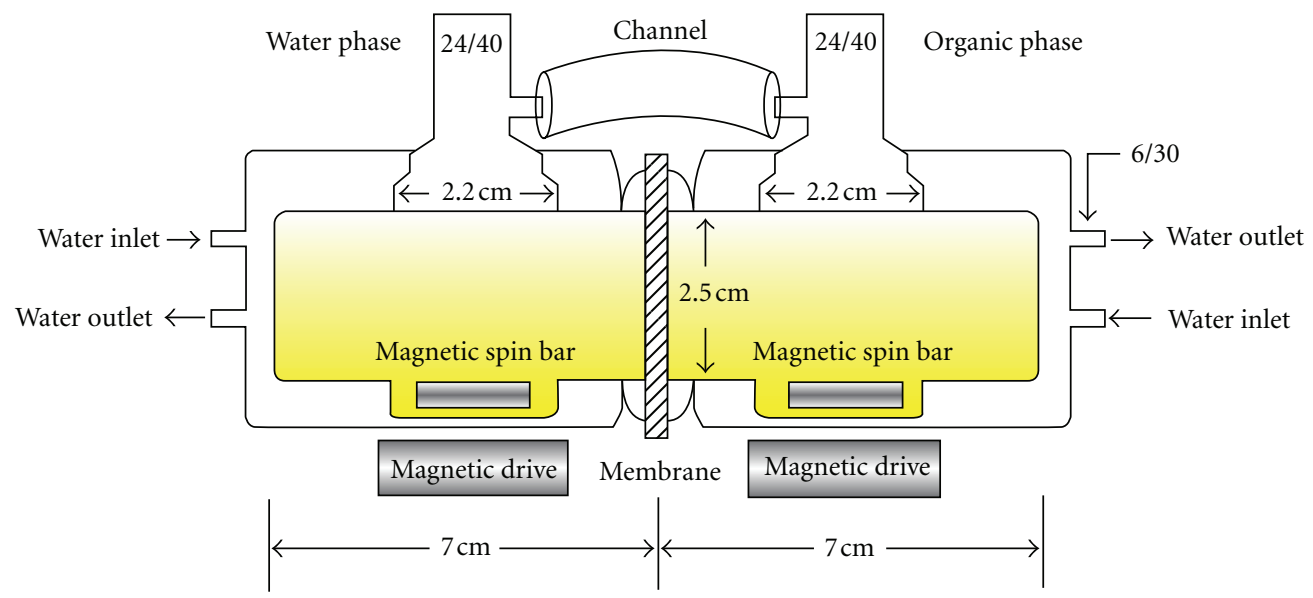

(c)

FIGURE 2: Schematic of (a) membrane reactor V1: membrane, 2; Teflon stir bar, 3; stainless stirrer, 4; membrane reactor, 5; magnetic stirrer, 6; mechanical stirrer, 7; sampling point, 8; cooling circulator bath [12]. (b) Membrane reactor H1. (c) Membrane reactor H2. 
TABLE 1: Advantages and disadvantages of three reactors.

\begin{tabular}{|c|c|c|c|}
\hline & V1 reactor & H1 reactor & $\mathrm{H} 2$ reactor \\
\hline Diameter of membrane $(\mathrm{cm})$ & 6.2 & 2.2 & 2.5 \\
\hline Area of membrane $\left(\mathrm{m}^{2}\right)$ & $3.02 \cdot 10^{-3}$ & $3.8 \cdot 10^{-4}$ & $4.91 \cdot 10^{-4}$ \\
\hline Working volume $\left(\mathrm{cm}^{3}\right)$ & 55 & 35 & 35 \\
\hline Activation energy ( $\mathrm{kcal} / \mathrm{mole})$ & 12.11 & 13.12 & 11.69 \\
\hline Turnover number $\left(\mathrm{s}^{-1}\right)$ & $1.53 \cdot 10^{-3}$ & $2.58 \cdot 10^{-3}$ & $2.74 \cdot 10^{-3}$ \\
\hline Recovery rate of phenol in $90 \mathrm{~min}\left(\mathrm{ppm} /\left(\operatorname{min~m}^{2}\right)\right)$ & 13794 & 45263 & 38452 \\
\hline Pressure drop & $\triangle$ & $\triangle$ & $\bigcirc$ \\
\hline Gravity & $\times$ & $\triangle$ & $\bigcirc$ \\
\hline Area of membrane & $\times$ & $\bigcirc$ & $\bigcirc$ \\
\hline Apparatus & $\triangle$ & 0 & 0 \\
\hline Cost & $\triangle$ & 0 & 0 \\
\hline Operating difficulty & $\triangle$ & $\bigcirc$ & $\bigcirc$ \\
\hline Reactivity & $\times$ & 0 & $\bigcirc$ \\
\hline
\end{tabular}

$\bigcirc$ good, $\triangle$ fair, $\times$ poor.

reactors: the slurry reactor and fixed-bed reactor usingquaternary ammonium poly(styrene-co-chloromethylstyrene) resin, to evaluate a liquid-solid-liquid triphase reaction. However, the catalyst was always suspended in the solution and could flow out of the reactor during a reaction. Hence, developing a method to secure the catalyst on the reactor bed is crucial to improve product and catalyst separation. A membrane reactor could solve these problems, but some design issues must be addressed to improve reaction rates.

\section{Membrane Reactor Design Problems}

Previous research [13] reported that the organic solution leaked into the aqueous solution during a reaction because gravity reduced the reactivity of the active site on the membrane in the vertical membrane reactor. Hence, the vertical membrane reactor was replaced with a horizontal membrane reactor to avoid the gravity problem, to test the reactivity of phenol allylation. The leaking phenomenon decreased in the horizontal membrane reactor. Wu and Lo [12] and H. S. Wu and Y. K. Wu [13] used the design shown in Figure 2(a). The reactor (V1) was used to recover phenol from simulated wastewater. The reaction system was prepared by pouring the aqueous solution into the bottom cell, covering the anion exchange membrane and locking the reactor. The organic solution was introduced into the top cell, starting the reaction.

Some engineering problems must be overcome in this system and the membrane structure is an important factor. Before the experiment, some bubbles may appear in the aqueous solution during the preparation step. This could influence the mass transfer of aqueous reactant from the bulk solution to the membrane. If the boiling points of both solvents (1-2 dichloroethane and water) are different, there is a large pressure drop between two cells, which forces the solution to pass through the membrane into the other phase because the membrane reactor is a closed system. If the density of the solution in the top cell is larger than in the other cells, gravity is also a problem. Gravity could force the top solution to pass through the membrane into the bottom phase. Hence, gravity, pressure, membrane, and bubbles influence reactivity in the reactor type, as shown in Figure 2(a). The sample was also only drawn from the top cell and not from the bottom cell.

H. S. Wu and Y. K. Wu [13] proposed that the membrane reactor $(\mathrm{H} 1)$ design shown in Figure 2(b) could solve these problems and produce better reactivity than membrane reactor V1. Moreover, the sample was simultaneously drawn from two phases in reactor $\mathrm{H} 1$, but from only one point in the top cell in membrane reactor V1, as shown in Figure 2(a). Reactor $\mathrm{H} 1$ has some disadvantages; for example, the solution is higher than the height of the membrane and the density of 1-2 dichloroethane is more than that of water. Although the gravity effect was less than in reactor V1, the organic phase still passes through the membrane during the long reaction time. Reactor $\mathrm{H} 1$ used a closed system for each cell; therefore, the pressure drop between two cells was large, which could be problematic.

Reactor H2 in Figure 2(c) was designed to compensate for these problems. The height of the solution was equal to that of the membrane and there was a channel tube between both phases, solving the effects of gravity and pressure. Table 1 shows the advantages and disadvantages of the three membrane reactors.

\section{Optimal Reactivity in Reactors H1 and H2 Using Respond Surface Methodology}

Increasing the concentration of the organic reactant (allylbromide) increases the reaction rate. In this case, increasing the concentration of organic reactants could also increase the mass transfer rate of the organic reactant because the mass transfer of the organic reactant from the organic phase to the membrane phase was slow. However, increasing aqueous reactant concentrations (phenol) could decrease the reaction rate. An increase in the concentration of aqueous reactants allows aqueous reactants to block the 


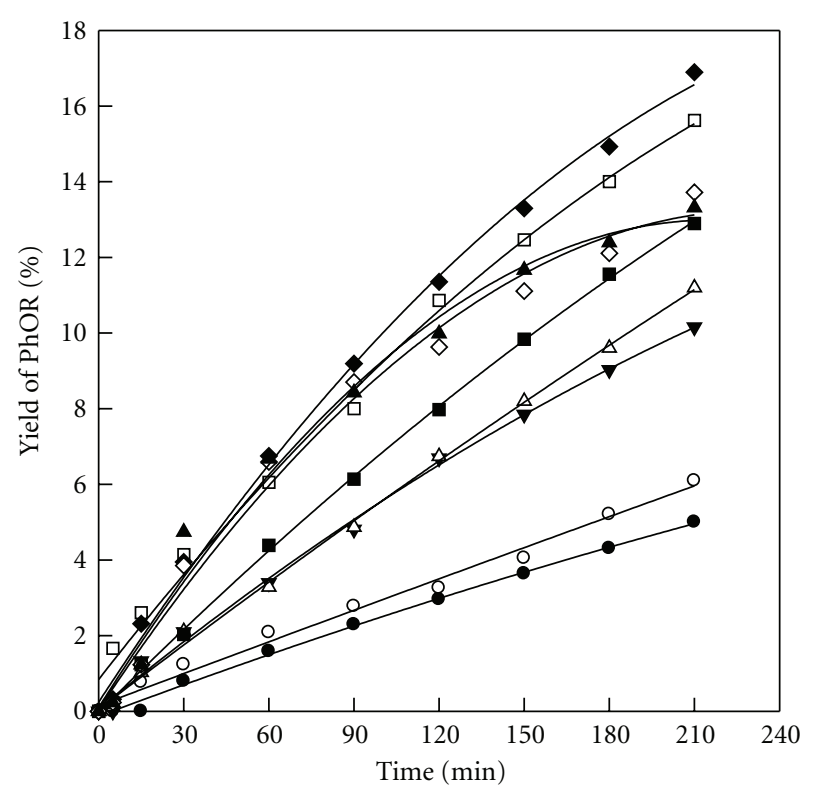

$\begin{array}{lll}\text { Molar ratio } & & \\ \bullet 1 & \Delta 4 & \diamond 7 \\ \circ 2 & \square 5 & \diamond 8 \\ \nabla 3 & \square 6 & \Delta 9\end{array}$

Figure 3: Effect of molar ratio of allylbromide to PhONa. $T=50^{\circ} \mathrm{C}$, agitation $=400 \mathrm{rpm}$. Aqueous phase $\left(35 \mathrm{~cm}^{3}\right)$ : deionized water, phenol $=0.011 \mathrm{~mol}, \mathrm{NaOH}=0.018$ mole. Organic phase $\left(35 \mathrm{~cm}^{3}\right)$ : $1,2-\mathrm{C}_{2} \mathrm{H}_{4} \mathrm{Cl}_{2}$, membrane reactor $\mathrm{H} 1$, membrane $=\mathrm{A} 172$.

membrane, decreasing the mass transfer rate [12]. Hence, the reaction mechanism in a liquid-liquid membrane phasetransfer catalyzed reaction is different from that in a liquidliquid phase-transfer catalyzed reaction. This study used the Respond Surface Methodology (RSM) [16-18] to investigate the reactivity of phenol allylation in $\mathrm{H} 1$ and $\mathrm{H} 2$ reactors.

The molar ratio of organic reactant (allylbromide) to aqueous reactant (phenol) was generally an important factor. The reaction rate increased in conjunction with the molar ratio of allylbromide to phenol. Molar ratios between 1 and 9 were tested in this system. After testing, the best molar ratio (7) was used in the next step. The result is shown in Figure 3. Organic and aqueous reactant concentrations affected the reaction rate. Previously, researchers wanting to obtain optimum conditions in traditional reaction kinetics used experimental runs, which increased the number of runs. This method was time consuming and expensive. This study used RSM to test different concentrations to examine the relationship between organic and aqueous reactant concentrations. The best molar ratio of organic to aqueous reactant concentrations was found and this ratio was used in the steepest ascent path method. After the experiment design, reaction rates were calculated to obtain (9).

$$
\begin{aligned}
R= & 2.47 \times 10^{-4}+3.8 \times 10^{-5}[\text { Phenol }] \\
& +1.18 \times 10^{-4}[\text { Allylbromide }]
\end{aligned}
$$

$$
\begin{aligned}
& -8 \times 10^{-5}\left[_{\text {Phenol }]^{2}}\right. \\
& -3.51 \times 10^{-3}[\text { Allylbromide }]^{2},
\end{aligned}
$$

where $R$ is the reaction rate $\left(\mathrm{mol} /\left(\mathrm{m}^{2} \cdot \mathrm{s}\right)\right)$. The respond surface of the reaction in reactor $\mathrm{H} 1$ is shown in Figure 4(a).

The turnover number is the number of substrate molecules converted to produce by one molecule of catalyst per unit of time when the reaction rate is maximal and the substrate is saturated. That is, the turnover number $\left(\mathrm{s}^{-1}\right)$ is the maximal mole of substrate consumed per catalyst per time. The turnover number is calculated using

$$
\text { Turnover Number }=\frac{R}{M_{c}},
$$

where $M_{c}$ is the amount of the catalyst per area $\left(\mathrm{mol} / \mathrm{m}^{2}\right)$. Based on previous research, the yield of allyl phenyl ether increased when the excess organic concentration increased. Figure 4(a) shows that after calculation, the optimal reaction rate was $8.54 \times 10^{-4} \mathrm{~mol} / \mathrm{s} \cdot \mathrm{m}^{2}$ when phenol and allylbromide were $7.41 \times 10^{-3} \mathrm{~mol}$ and $0.106 \mathrm{~mol}$, respectively. The average membrane weight was $0.086 \mathrm{~g}$ and the ion-exchange capacity was $1.6 \mathrm{mmol} / \mathrm{g}$; therefore, the mole of the catalyst was $1.22 \times$ $10^{-4} \mathrm{~mol}$. The turnover number was $2.58 \times 10^{-3} \mathrm{~s}^{-1}$ at $328 \mathrm{~K}$. Previous researchers [12] found a turnover number of $1.53 \times$ $10^{-3} \mathrm{~s}^{-1}$ in reactor V1, as shown in Figure 2(a). This value was smaller than that of reactor $\mathrm{H} 1$.

Table 1 shows the similar optimal reactivity of reactor $\mathrm{H} 2$. The optimal reaction rate and turnover number for reactor $\mathrm{H} 2$ are larger than those for reactor H1. Figure 4 shows that the operating concentration of allybromide or phenol in reactor $\mathrm{H} 2$ is also larger than those for reactor $\mathrm{H} 1$. Therefore, reactor $\mathrm{H} 2$ performs better than reactor $\mathrm{H} 1$.

\section{Effect of Membrane Structure}

Wu and Lo [12] showed that the reaction rate increased with an increasing molar ratio of allylbromide to phenol. Figure 5 shows that the allyl phenyl ether yield varies with different types of membranes. To determine what occurred in the reaction, different membrane types were tested to measure contact angles. This is shown in Figures 6 and 7.

The dry A172 membrane and laboratory-produced base membranes were polymeric membranes. Generally, the polymer membranes were hydrophobic. The contact angles of the dry A172 membrane and laboratory-produced base membranes decreased with an increasing concentration of phenol in the aqueous solution. The contact angles for the dry A172 membrane in aqueous or organic solvents were larger than those for the laboratory-produced base membranes. This could indicate that the interaction between solvents and the membrane of the laboratory-produced membranes was larger than the interaction of the A172 membrane. The reaction rate for laboratory-produced membranes could be higher than for the A172 membrane. For wet membranes, the contact angles were zero because the solvent drops were drawn into the membrane. 


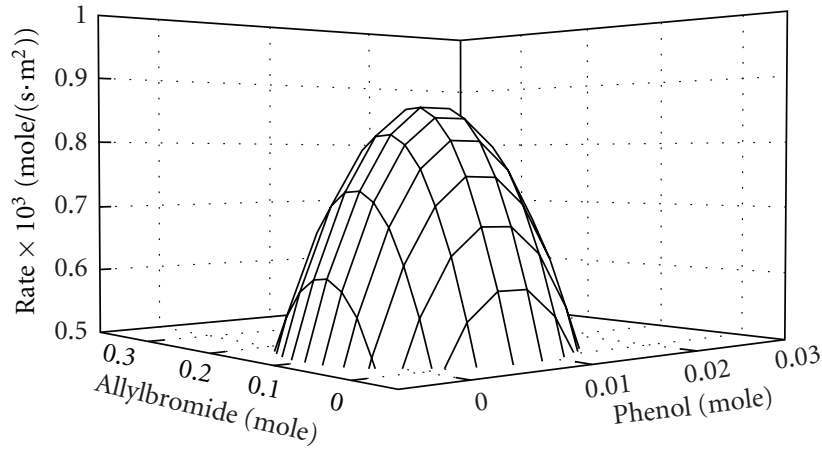

(a)

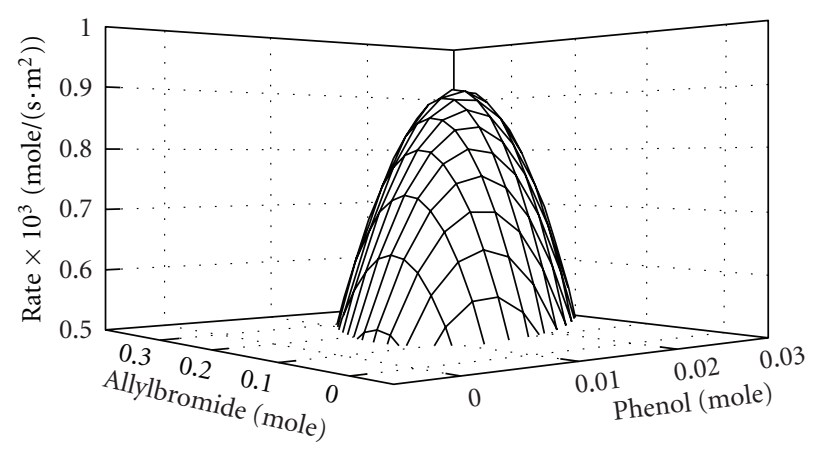

(b)

FIgURE 4: Respond surface of reaction in membrane reactors (a) H1 and (b) H2.

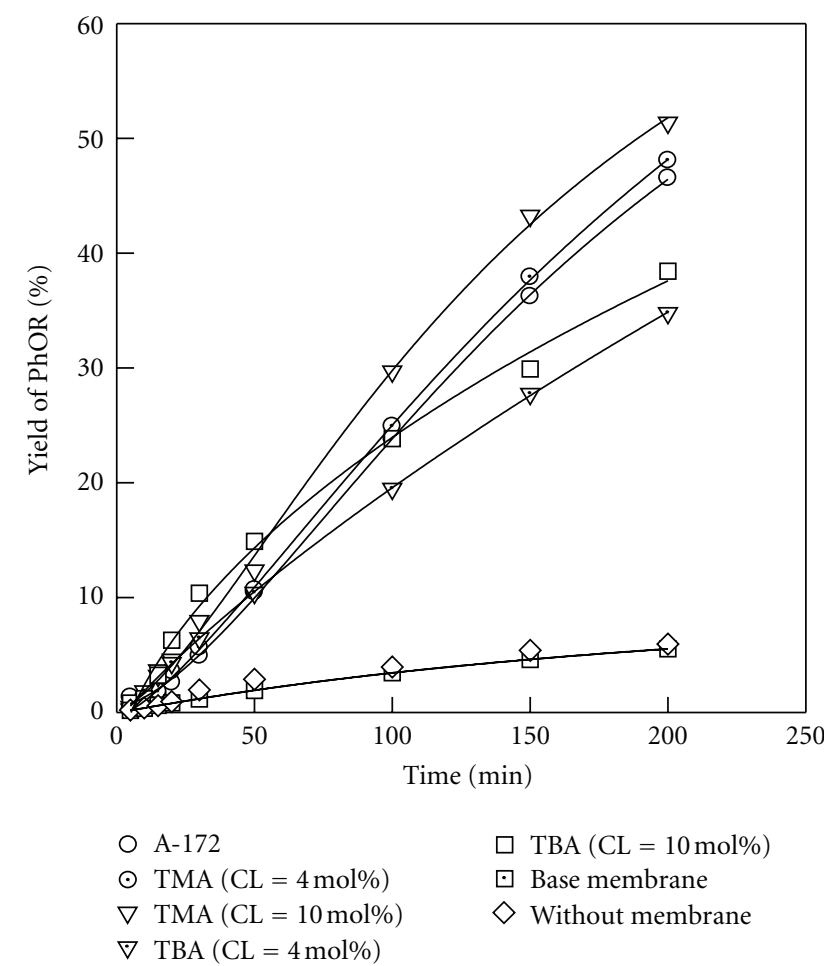

FIGURE 5: PhOR yield from various membranes with an excess of organic reactant. $45^{\circ} \mathrm{C}, 400 \mathrm{rpm}$. Aqueous phase $\left(55 \mathrm{~cm}^{3}\right)$ : $0.004 \mathrm{~mol}$ of phenol, $\mathrm{NaOH}=0.0064 \mathrm{~mol}$. Organic phase $\left(55 \mathrm{~cm}^{3}\right)$ : $1,2-\mathrm{C}_{2} \mathrm{H}_{4} \mathrm{Cl}_{2}, 0.06 \mathrm{~mol}$ of $\mathrm{C}_{3} \mathrm{H}_{5} \mathrm{Br}$. Data quoted from $\mathrm{Wu}$ and Lo [12].

Figure 8 shows that the water content decreased with increasing crosslinkage when the ion-exchange capacity did not change. Because the physical strength of the membrane increased with crosslinkage, it was difficult for water to exist in the membrane, and the swelling decreased.

The aqueous ion-exchange reaction of phenolate ion $\left(\mathrm{PhO}^{-}\right)$and bromide ion $\left(\mathrm{Br}^{-}\right)$is shown by

$$
\mathrm{Q}^{+} \mathrm{Br}^{-}+\mathrm{PhO}^{-} \stackrel{k_{f}}{\rightarrow} \mathrm{Q}^{+} \mathrm{PhO}^{-}+\mathrm{Br}^{-},
$$

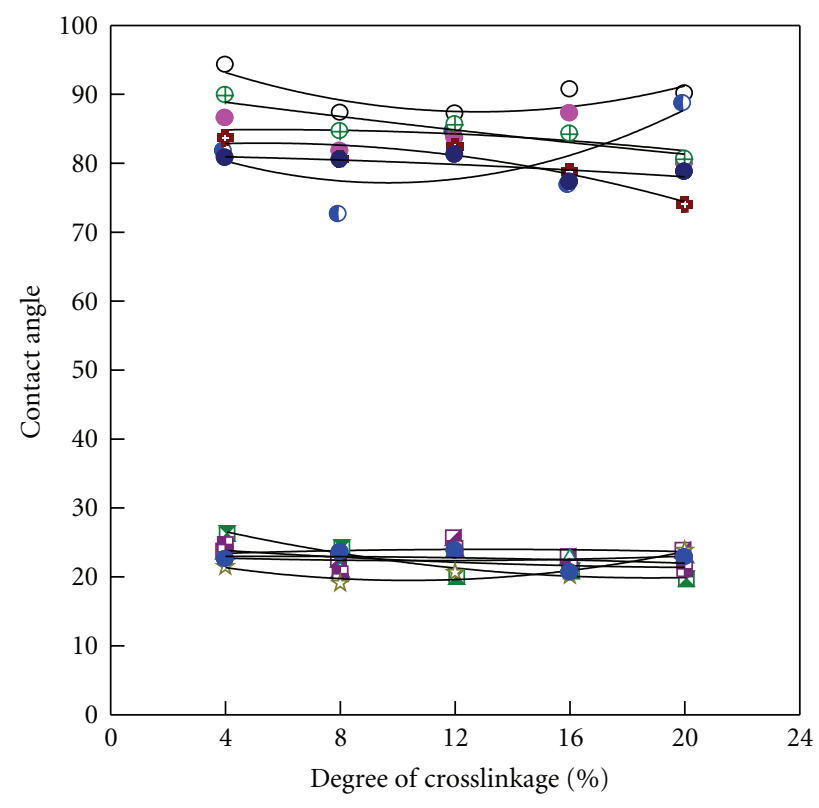
○ $0 \mathrm{ppm}$
$\oplus 4000 \mathrm{ppm}$
D 5 times
- $1000 \mathrm{ppm}$
- $5000 \mathrm{ppm}$
ㅁ 10 times
- $2000 \mathrm{ppm}$
च 0 time
th 15 times
+ 3000 ppm
$\triangle 1$ time
- 20 times

Figure 6: Contact angles of laboratory-produced base membranes with different degrees of crosslinkage with different concentrations of phenol and molar ratios of allylbromide to phenol.

where $Q^{+}$is a phase-transfer catalyst. The reaction expression is:

$$
r=-\frac{d\left[\mathrm{PhO}^{-}\right]}{d t}=k_{f}\left[\mathrm{PhO}^{-}\right]\left[Q^{+} \mathrm{Br}^{-}\right] .
$$

The $k_{f}$ value was calculated from the slope in Figure 9 (upper panel) using the initial reaction rate method. The reaction rate has an optimal value. $k_{f}$ decreased with increasing initial amounts of PhONa. This verifies that increasing concentrations of aqueous reactant does not increase the reaction rate, as shown in Figure 9 (lower panel). Therefore, the contact angle, water content, and ion exchange of 


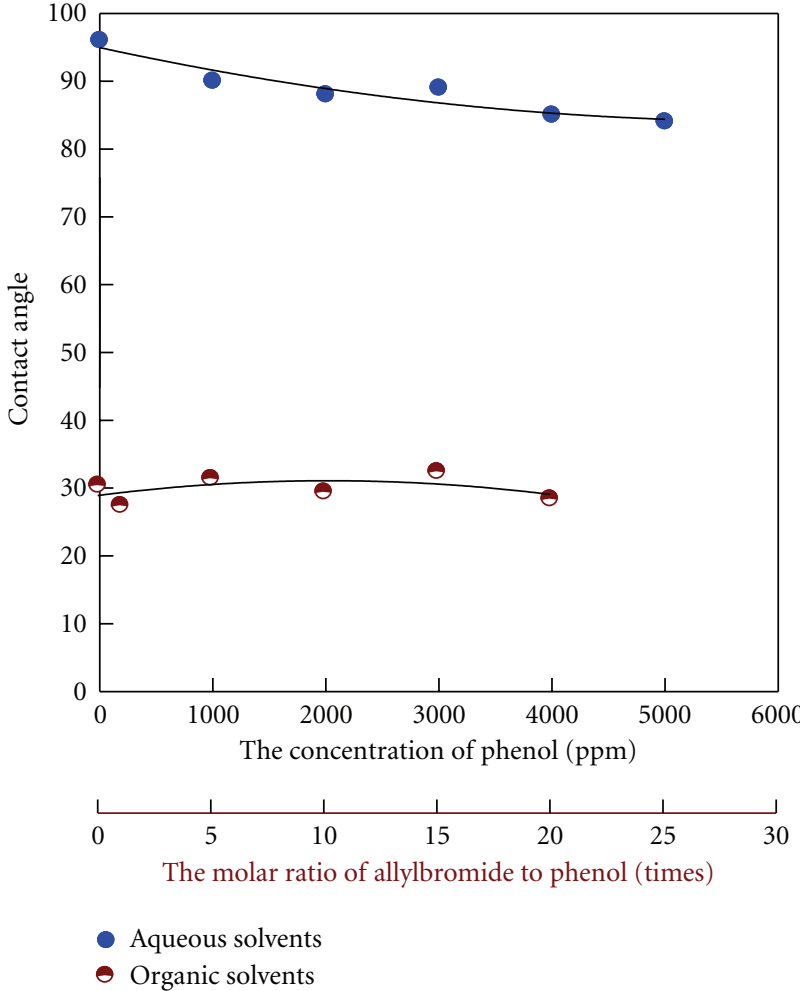

Figure 7: Contact angles of dry A172 membrane with different concentrations of phenol and molar ratios of allylbromide to phenol.

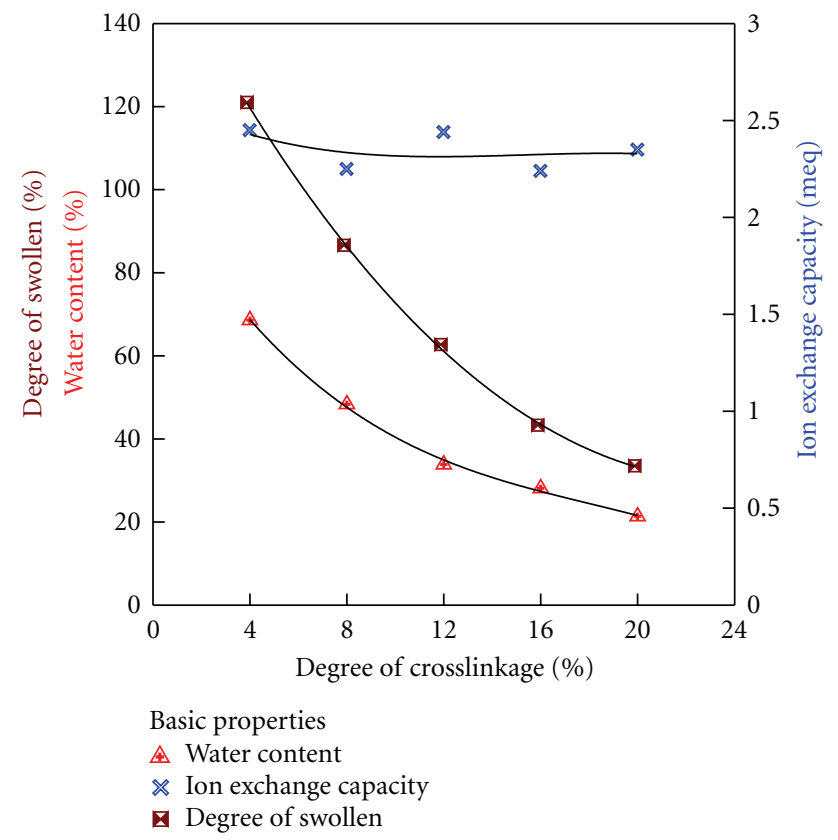

FIGURE 8: Effects of degree of crosslinkage on swelling, water content, and ion exchange capacity of a tetra-methylamine membrane.

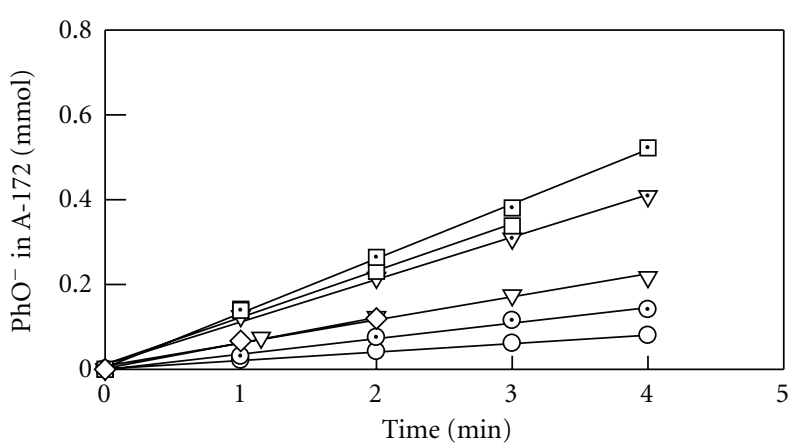

$\begin{array}{ll}\operatorname{PhONa}_{(\mathrm{a})}(\mathrm{mmol}) & \\ \bigcirc 0.4 & \square 4 \\ \odot 0.7 & \square 5 \\ \nabla 1.5 & \diamond 7 \\ \nabla 3 & \end{array}$

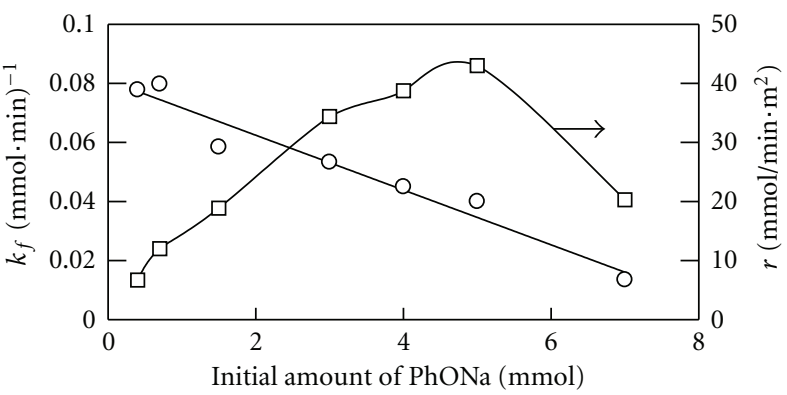

Figure 9: $\mathrm{PhO}^{-}$in $\mathrm{A} 172$ versus time and the effect of PhONa on the forward ion-exchange rate. $65^{\circ} \mathrm{C}, 400 \mathrm{rpm}, 30.2 \mathrm{~cm}^{2}$ of $\mathrm{A}-172$ membrane, aqueous phase $55 \mathrm{~cm}^{3}$.

phenolate ions with bromide in the membrane are essential for applying this membrane technique to phase-transfer catalysis.

\section{Conclusion}

Gravity and pressure are important factors in reactor design. The catalytic reactivity in the $\mathrm{H} 2$ reactor design was better than in the V1 reactor. The RSM could be used to obtain the optimal turnover number and reaction rate to verify the reactivity of a catalyst in a membrane. For phase-transfer catalytic membrane systems to perform well, the membrane structure for reactants and solvents must be studied to obtain optimal conditions.

\section{Acknowledgment}

We would like to thank the National Science Council of Taiwan for financially supporting this research under Grant nos. NSC 94-2214-E155-004 and 95-2214-E155-006.

\section{References}

[1] V. V. Dehmlow and S. S. Dehmlow, Phase Transfer Catalysis, Chemie, Weinheim, Germany, 1993.

[2] C. M. Starks, C. L. Liotta, and M. Halpern, Phase-Transfer Catalysis, Fundamentals, Applications, and Industrial Perspectives, Chapman \& Hall, New York, NY, USA, 1994. 
[3] H. M. Yang and H. S. Wu, "Interfacial mechanism and kinetics of phase-transfer catalysis," in Interfacial Catalysis, A. G. Volkov, Ed., vol. 285, chapter 11, Marcel Dekker, 2003.

[4] V. T. Zaspalis, W. Van Praag, K. Keizer, J. G. Van Ommen, J. R. H. Ross, and A. J. Burggraaf, "Reactions of methanol over catalytically active alumina membranes," Applied Catalysis, vol. 74, no. 2, pp. 205-222, 1991.

[5] G. D. Yadav and P. H. Mehta, "Theoretical and experimental analysis of capsule membrane phase transfer catalysis: selective alkaline hydrolysis of benzyl chloride to benzyl alcohol," Catalysis Letters, vol. 21, no. 3-4, pp. 391-403, 1993.

[6] Y. Okahata and K. J. Ariga, "Functional capsule membranes. 27. A new type of phase-transfer catalysts (PTC). Reaction of substrates in the inner organic phase with the outer aqueous anions catalyzed by PTC grafted on the capsule," Journal of Organic Chemistry, vol. 51, p. 5064, 1986.

[7] Y. Mizutani, R. Yamane, H. Ihara, and H. Motomura, "Studies of Ion Exchange Membraness. XVI. The preparation of ion exchange membranes by the "Paste Method"', Bulletin of The Chemical Society of Japan, pp. 361-366, 1963.

[8] Y. Mizutani, R. Yamane, and H. Motomura, "Studies of Ion Exchange Membranes. XXII. Semicontinuous preparation of ion exchange membrane by the paste method," Bulletin of The Chemical Society of Japan, pp. 689-694, 1964.

[9] Y. Mizutani, "Studies of Ion Exchange Membraness. The tetrahydrofuran extraction of the ion-exchange membrane and its base membrane prepared by the "Paste Method"," Bulletin of The Chemical Society of Japan, vol. 42, no. 1969, pp. 2459-2463, 1969.

[10] H. P. Gregor, H. Jacobson, R. C. Shair, and D. M. Wetstone, "Interpolymer ion-selective membranes. I. Preparation and characterization of polystyrenesulfonic acid-dynel membranes," Journal of Physical Chemistry, vol. 61, p. 141, 1957.

[11] P. Zschocke and D. Quellmatz, "Novel ion exchange membranes based on an aromatic polyethersulfone," Journal of Membrane Science, vol. 22, pp. 325-332, 1985.

[12] S. Wu and M. H. Lo, "Modeling and kinetics of allylation of phenol in a triphase-catalytic membrane reactor," American Institute of Chemical Engineers, vol. 51, pp. 960-970, 2005.

[13] H. S. Wu and Y. K. Wu, "Preliminary study on the characterization and preparation of quaternary ammonium membrane," Industrial \& Engineering Chemistry Research, vol. 44, p. 1757, 2005.

[14] H. S. Wu and C. S. Wang, "Liquid-solid-liquid phasetransfer catalysis in sequential phosphazene reaction: kinetic investigation and reactor design," Chemical Engineering Science, vol. 58, no. 15, pp. 3523-3534, 2003.

[15] H. S. Wu, "Catalytic activity and kinetics of liquid-solidliquid phase-transfer catalysts," in New Developments in Catalysis Research, L. P. Bevy, Ed., chapter 1, pp. 1-38, Nova Science Publishers, 2005.

[16] G. E. P. Box and J. S. Hunter, "Multi-factor experimental designs for exploring response surfaces," Annals of Mathematical Statistics, vol. 28, p. 195, 1957.

[17] G. E. P. Box and K. B. J. R. Wilson, "On the experimental attainment of optimum conditions," Journal of the Royal Statistical Society B, vol. 13, p. 1, 1951.

[18] J. J. Cilliers, R. C. Austin, and J. P. Tucker, "An evaluation of formal experimental design procedures for hydrocyclone modelling," in Proceeding of the 4th International Conference of Hydrocyclones, L. Svarovsky and M. T. Thew, Ed., pp. 31-49, Kluwer Academic Publishers, Southampton, UK, 1992. 

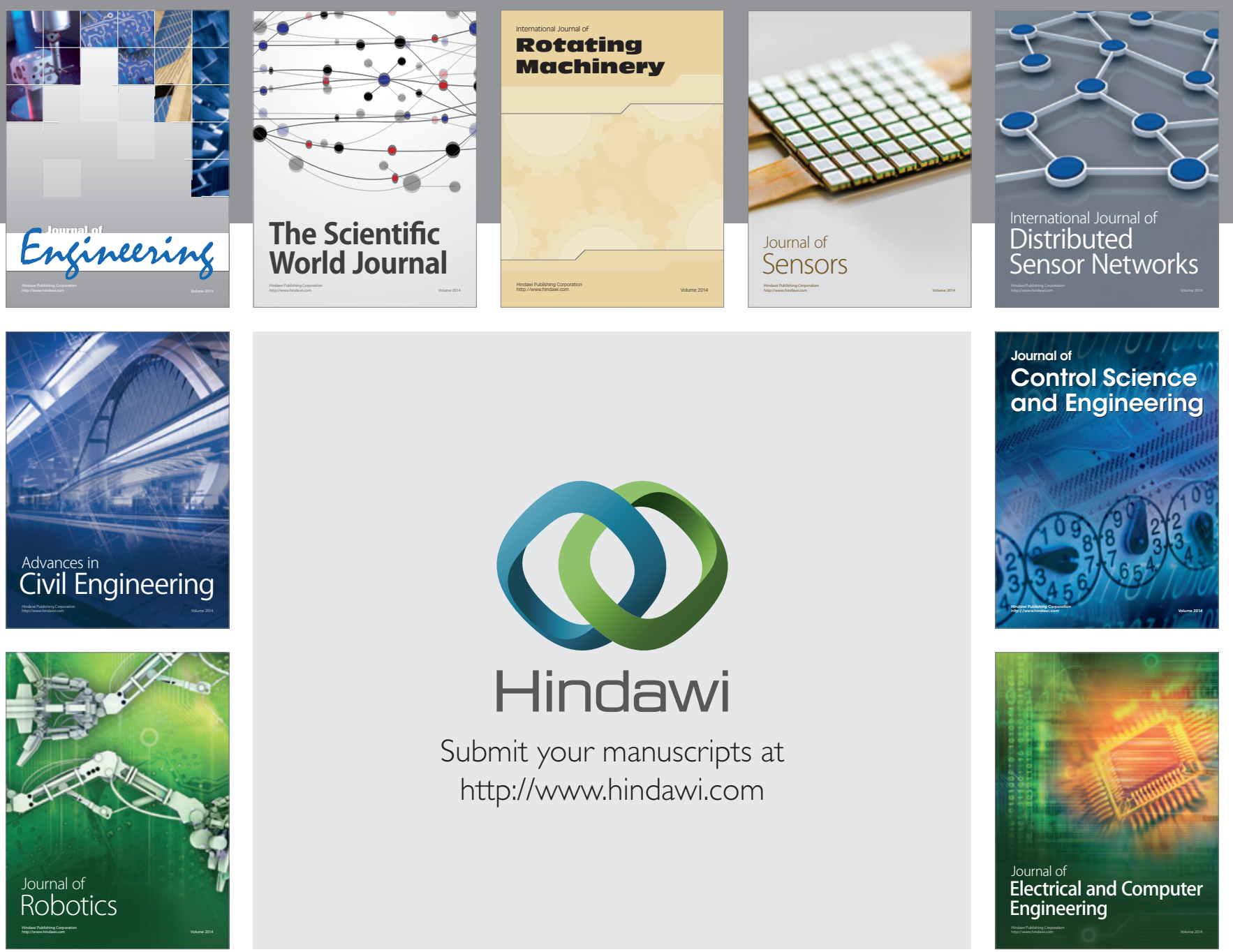

Submit your manuscripts at

http://www.hindawi.com
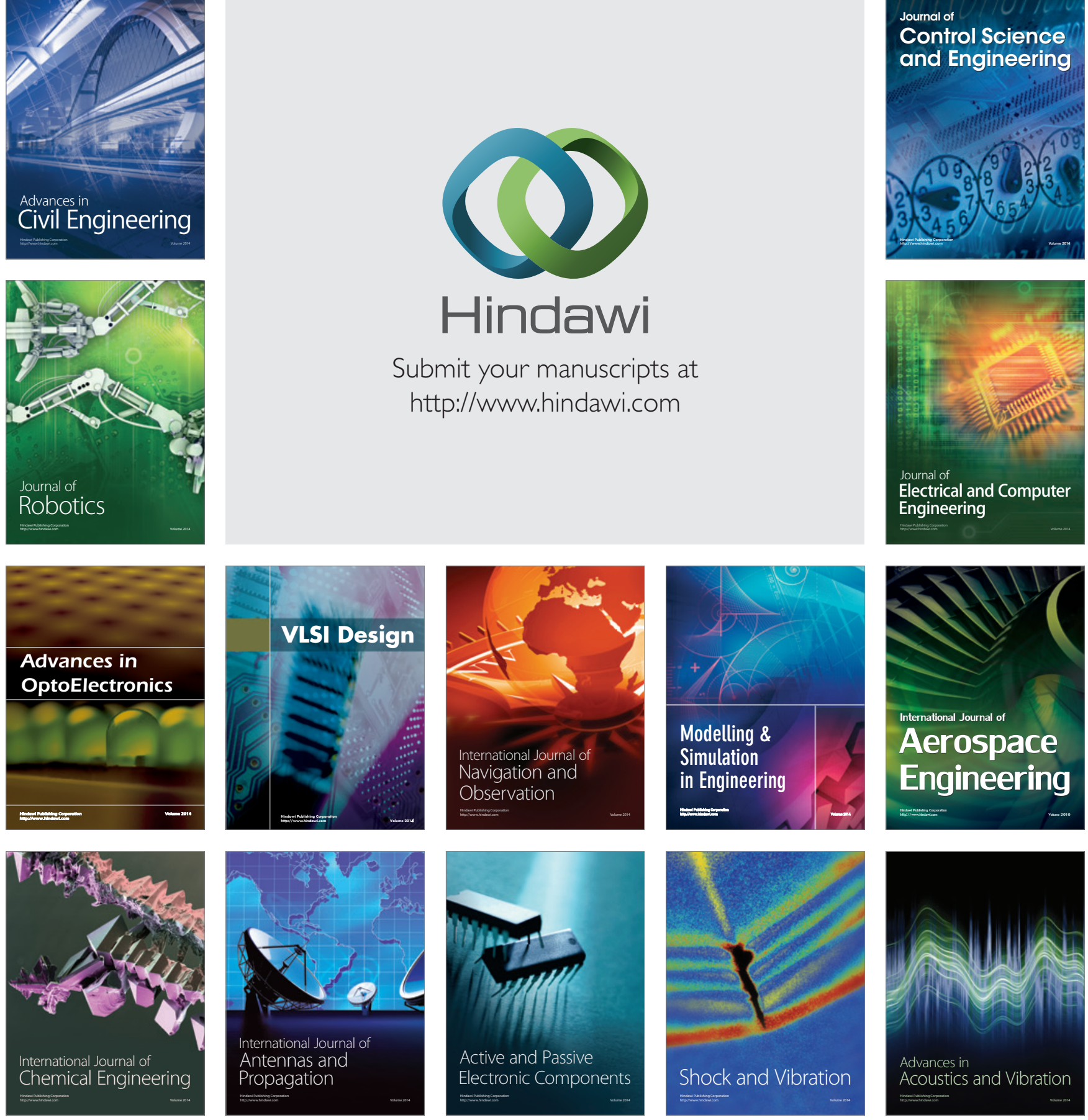